\title{
Psychometric properties of the Arabic-validated Severe Respiratory Insufficiency Questionnaire for the assessment of Health-Related Quality of Life in patients on home mechanical ventilation
}

Salah Zeineldine ( $\boldsymbol{\nabla}$ sz01@aub.edu.lb )

American University of Beirut Medical Center

Marwan Alawieh

American University of Beirut Medical Center

Mohamad Khatib

American University of Beirut Medical Center

Rania Bzeih

American University of Beirut Medical Center

Lilian Ghandour ( $D$ lg01@aub.edu.Ib)

American University of Beirut

Abla Sibai

American University of Beirut

\section{Research Article}

Keywords: Health-related quality of life, Home mechanical ventilation, Respiratory Failure, Validation

Posted Date: February 18th, 2021

DOl: https://doi.org/10.21203/rs.3.rs-195413/v1

License: (c) (i) This work is licensed under a Creative Commons Attribution 4.0 International License.

Read Full License 


\section{Abstract}

\section{Background/objectives:}

Assessment of Health-Related Quality of Life (HRQL) in patients with chronic respiratory insufficiency requiring Home Mechanical Ventilation (HMV) needs a valid measurement tool. The Severe Respiratory Insufficiency (SRI) questionnaire, originally developed in German, has been translated into different languages and tested in different contexts, except in Arabic-speaking populations of Arab world. The objective of this study is to validate the Arabic version of the SRI questionnaire from its original German version.

\section{Methods:}

Forward/backward translations between German and Arabic were conducted. The final Arabic version was administered to 149 patients (53 males - 96 females, age 69.8 \pm 10 years) receiving HMV recruited from outpatient clinics. Patients were scheduled for a home visit during which the Arabic SRI and the 36Item Short-Form Health Survey (SF-36) questionnaires were administered; data on sociodemographic and medical history were also collected. Dimensionality internal construct validity were assessed using exploratory factor analysis; internal consistency of the unidimensional scale and its subscales was also assessed using Cronbach's alpha. External nomological validity was tested by assessing correlation between the SRI and SF-36 questionnaires.

\section{Results:}

PCA scree plot indicated the presence of only one factor that explained $63 \%$ of the total variability. The Cronbach alpha for the total scale was 0.897 (ranged between 0.73 and 0.87 for all subscales).

Correlation between the SRI and SF-36 was highest amongst comparable subscales yielding $r=0.81$ and $r=0.74(P<0.01)$.

\section{Conclusion \& Recommendations:}

The Arabic SRI is a reliable and valid tool for assessing HRQL in patients with chronic respiratory insufficiency receiving home mechanical ventilation.

\section{Introduction}

Health-related quality of life (HRQL), which is comprised of various health components related to functional capabilities, physical conditions, psychological well-being, and social functioning, is a key in evaluating outcomes of clinical practice and medical interventions [1, 2]. Several tools have been developed and used to assess HRQL, particularly for patients with chronic conditions; these include the Sickness Impact Profile [3] and the 36-Item Short-Form Health Survey (SF-36) [4] among others. These tools, however, examine the general health status regardless of the underlying disease. In the field of pulmonary medicine, disease-specific scales have been developed and validated, and these include the 
Chronic Respiratory Disease Questionnaire [5] and the St. George's Respiratory Questionnaire [6] both of which assess fastidious issues related to patients with chronic obstructive pulmonary disease (COPD).

Patients with chronic respiratory insufficiencies, whether caused by obstructive (i.e. COPD) or restrictive ventilatory disorders (i.e. neuromuscular diseases (NMD), restrictive chest wall disorders (RWCD), lung fibrosis, and obesity hypoventilation syndrome (OHS)) are of medical concern because they represent a unique group given the severe limitations and comorbid effects of their respiratory dearth. One main intervention for these patients is non-invasive home mechanical ventilation (HMV) that is mostly delivered via a nasal or facial mask. Despite HMV's proven benefits in improving clinical and physiological parameters specific to patients with severe respiratory insufficiency $[7,8,9,10,11,12]$, the continued monitoring of the quality of life of these patients remains crucial to prevent complications and improve their survival rates [13]. Evaluation of their quality of life has been typically done using the aforementioned generic and disease-specific scales ([14], [10], [15], [16]). Yet, these scales lack proper assessment of the important characteristics and specific symptoms exclusive to this patient population leading to an imperfect evaluation of their quality of life $[14,17]$. For this reason, the Severe Respiratory Insufficiency (SRI) questionnaire was developed first by German researchers to assess central aspects relevant to this patient population [17]. The original SRI is a multidimensional HRQL tool with high psychometric properties (Cronbach's a coefficient of the summary scale was 0.89 and at least 0.7 in all subscales) [17]. The SRI questionnaire has been translated into different languages (e.g. English, Spanish, Norway, Japanese, Chinese, and Greek) and tested in different contexts [18, 19, 20, 21, 22, 23]. The aim of the current study is to develop a transculturally adapted version of the SRI questionnaire in Arabic language, examine its reliability and validity among patients with chronic respiratory insufficiency. The Arab region consists of 22 countries, while 25 countries have Arabic as one of their official language.

\section{Methods}

\subsection{Patients and study design}

Ethical approval for the study was obtained from the Institutional Review Board at the American University of Beirut, Lebanon. A convenient sample of patients with chronic respiratory insufficiency receiving HMV was identified from clinics specialized in pulmonary medicine across all Lebanon between March 2016 and May 2018. Eligible patients were contacted by their attending physicians who explained the objectives of the study and took their approval to be contacted by the research team. Patients were then approached over the phone for obtaining preliminary consent to participate in the study and were screened for eligibility using the inclusion/exclusion criteria. All patients receiving HMV and clinically stable for more than one month before enrolment were eligible for the study. Patients with a tracheostomy tube, a history of left-sided congestive failure and an exacerbation during the preceding month were not eligible to participate. Consenting eligible patients were visited in their homes for face-toface interviews. Each interview took around 10 minutes to be completed.

\subsection{Measures}


The SRI scale is a multidimensional instrument comprised of 49 items, and seven subscales including: Respiratory Complaints (SRI-RC), Physical Functioning (SRI-PF), Attendant Symptoms and Sleep (SRI-AS), Social Relationships (SRI-SR), Psychologic Well-being (SRI-WB), Anxiety (SRI-AX) and Social Functioning (SRI-SF). The SRI questionnaire assesses the patients' condition during the preceding one week based on his/her level of agreement rated using a five Likert-scale from "strongly agree" to "strongly disagree". Typically, subscale scores are generated or a total scale score is generated (SRI-SS) yielding a score ranging between 0 and 100, with higher scores indicating a better quality of life.

\section{SF36}

Additionally, we administered the SF-36 item scale to measure the general quality of life among our sample. The SF-36 consists of eight subscales measuring diverse components of health status with a score ranging between 0 and 100; with higher scores indicating better health. The eight subscales are the following: SF-36-PF = Physical Functioning; SF-36-RP = Role Physical; SF-36-BP = Bodily Pain; SF-36-GH $=$ General Health; SF-36-VT = Vitality; SF-36-SF = Social Functioning; SF-36-RE = Role-Emotional; SF-36$\mathrm{MH}=$ Mental Health [4].

\section{Sociodemographic and other correlates}

Sociodemographic data collected included sex, age, highest educational level, occupation, as well as living arrangements (e.g. who lives with you at home, and who cares for you at home). Additionally, information on smoking behavior for both cigarettes and water-pipe were recorded including current status, age at initiation and quitting (for ex-smokers), and quantity smoked per day, thus allowing the calculation of pack-years. Information about the underlying diagnosis leading to respiratory failure as well as the main indication for the initiation of HMV were assessed. Finally, the patient was asked to specify the time in years s/he have been using the therapy at home and the hours of use during the day.

\subsection{Cross Cultural Adaptation}

The main purpose behind cross-cultural adaptation is to come up with comparable versions between the original scale (German) and the current version (Arabic). This also includes cultural adaption for each item to ensure reflection at the cultural context.

Stage I: initial translation

The validation procedure started with translating the original Deutsch scale to Arabic.

First, two forward translations into the Arabic language were undertaken by two different professional sworn translators, whose native language was Arabic.

Stage II: synthesis of the translation 
Four authors (M.A., L.G., A.S., and M.K.) reviewed and discussed the two translations. It is worth noting that there were no major differences in items between T1 and T2. Minor discrepancies were discussed by the research team who carefully checked any discrepancies between the two translations against the validated English version and a consolidated Arabic version was produced.

Stage III: back translation (BT)

The Arabic version was then back-translated to German by another independent translator, blinded to the original German version, and was compared with the original instrument by a fourth translator. This step was undertaken to ensure correctness of the forward translations. Discrepancies were corrected accordingly, and a pre-final Arabic version was produced.

Stage IV: test of the pre-final version

The version was then piloted and tested among 10 patients with SRI and receiving HMV, identified and recruited in a similar manner through which the study sample was assembled. No amendments were done as the participants highlighted that the Arabic SRI was easy and understandable. The version resulting from the pilot test was used within the data collection tools for the validation study.

\section{Analysis}

Descriptive statistics were generated for the patients' socio-demographics, disease characteristics, HMV utilization, general quality of life scores, and SRI scores. Principal Components Analysis (PCA) was used to explore the number of underlying factors for SRI scale, and eigenvalues, the scree plot, and the percentage of variance explained were evaluated. The internal consistency of the scale and its subscales were assessed by calculating the Cronbach alpha coefficient. Values of Cronbach's alpha above 0.7 were considered acceptable [24]. The internal construct validity was assessed using Confirmatory Factor Analysis (CFA) assuming the factor structure as per the original SRI. The model fit was tested through Root Mean Square Error of Approximation (RMSEA) and the Comparative Fit Index (CFI). Values of RMSEA less than or equal to 0.05 indicate a good fit, between 0.05 and 0.08 indicate an adequate fit, and values greater than 0.10 indicate a poor fit. A lower bound of RMSEA $90 \%$ confidence interval (CI) less than 0.05 , as well as an upper limit less than 0.08 , indicate a good fit, whereas a maximum upper bound of 0.10 indicates an acceptable fit. Values of $\mathrm{CFI} \geq 0.95$ indicate a good fit, values less than 0.95 but greater than 0.90 indicate an adequate fit, and values $\leq 0.90$ indicate a poor fit [25]. External nomological validity was finally assessed by evaluating the correlation between the Arabic SRI and the Arabic SF-36. All statistical analyses were done using the Statistical Package for Social Sciences (SPSS) version 23.0.

\section{Results}

\subsection{Patients Profile}

A total of 149 patients completed the questionnaire in $15 \pm 4$ minutes with a $100 \%$ item response, except for the item 31 "My marriage/relationship is suffering because of my illness"; forty-eight percent of 
patients did not respond to this item since they were not married or in a relation at time of filling the questionnaire. The mean age of the sample was $69.8 \pm 10$, and constituted of $53(35.5 \%)$ males. 31 (21\%) patients were current smokers, 93 (62\%) previous smokers, and 25 (17\%) had never smoked. The majority of patients had COPD $(n=114)$ among other diagnostic groups including neuromuscular disorders $(n=$ 8), restrictive chest wall disorders $(n=4)$ and obesity-hypoventilation syndrome $(n=7)$, in addition to one lung fibrosis case. Fifteen other patients had a combination of more than one diagnosis. HMV had been utilized for a mean of $32.6 \pm 36.2$ months, and was applied for a mean of $8.1 \pm 3.9$ hours per day.

\subsection{Construct validity}

Principal components analysis of the 49 items indicated the presence of one common factor (as per the scree plot) explaining $63 \%$ of the total variation in the questionnaire (Fig. 1).

Initial CFA on each subscale did not show a good fit. Modification indices suggested the correlation of residual errors for some items in the SRI-RC, SRI-AS, SRI-WB and SRI-SF sub-scales to improve fit. This resulted in an acceptable RMSEA $90 \% \mathrm{Cl}$ for the subscales RC, WB \& SF (upper bound didn't exceed 0.1). Moreover, CFI results reflected a good model fit of the observed values in all subscales (above 0.9) (Table 1). The construct of the SRI-AS sub-scale following modification of residual errors is shown an example in Fig. 2. 
Table 1

Confirmatory Factor Analysis Results

\begin{tabular}{|c|c|c|c|c|c|c|c|}
\hline Scale & SRI-RC & SRI-PF & SRI-AS & SRI-SR & SRI-WB & SRI-AX & SRI-SF \\
\hline & Item & Item & Item & Item & Item & Item & Item \\
\hline & $\begin{array}{l}\text { [SRI02] } \\
0.61\end{array}$ & $\begin{array}{l}\text { [SRI01] } \\
0.43\end{array}$ & $\begin{array}{l}\text { [SRI06] } \\
0.39 \\
(0.35)\end{array}$ & $\begin{array}{l}\text { [SRI07] } \\
0.62\end{array}$ & $\begin{array}{l}\text { [SRI04] } \\
0.59\end{array}$ & $\begin{array}{l}\text { [SRI08] } \\
0.63\end{array}$ & $\begin{array}{l}\text { [SRIO3 } \\
0.55 \\
(0.58)\end{array}$ \\
\hline & $\begin{array}{l}\text { [SRI05] } \\
0.73 \\
(0.74)\end{array}$ & $\begin{array}{l}\text { [SRI16] } \\
0.57\end{array}$ & $\begin{array}{l}\text { [SRI09] } \\
0.61\end{array}$ & $\begin{array}{l}\text { [SRI10] } \\
0.49\end{array}$ & $\begin{array}{l}\text { [SRI20] } \\
0.69\end{array}$ & $\begin{array}{l}\text { [SRI13] } \\
0.68\end{array}$ & $\begin{array}{l}\text { [SRI15] } \\
0.81 \\
(0.84)\end{array}$ \\
\hline & $\begin{array}{l}\text { [SRI12] } \\
0.561\end{array}$ & $\begin{array}{l}\text { [SRI32] } \\
0.75\end{array}$ & $\begin{array}{l}\text { [SRI11] } \\
0.26 \\
(0.21)\end{array}$ & $\begin{array}{l}\text { [SRI21] } \\
0.82\end{array}$ & $\begin{array}{l}\text { [SRI30] } \\
0.69\end{array}$ & $\begin{array}{l}\text { [SRI26] } \\
0.63\end{array}$ & $\begin{array}{l}\text { [SRI23] } \\
0.38 \\
(0.37)\end{array}$ \\
\hline & $\begin{array}{l}\text { [SRI19] } \\
0.830\end{array}$ & $\begin{array}{l}\text { [SRI33] } \\
0.77\end{array}$ & $\begin{array}{l}\text { [SRI14] } \\
0.21 \\
(0.16)\end{array}$ & $\begin{array}{l}\text { [SRI27] } \\
0.35\end{array}$ & $\begin{array}{l}\text { [SRI34] } \\
0.39\end{array}$ & $\begin{array}{l}\text { [SRI28] } \\
0.84\end{array}$ & $\begin{array}{l}\text { [SRI31] } \\
0.70\end{array}$ \\
\hline & $\begin{array}{l}\text { [SRI22] } \\
0.568\end{array}$ & $\begin{array}{l}\text { [SRI41] } \\
0.51\end{array}$ & $\begin{array}{l}\text { [SRI17] } \\
0.84 \\
(0.82)\end{array}$ & $\begin{array}{l}\text { [SRI43] } \\
0.83\end{array}$ & $\begin{array}{l}\text { [SRI36] } \\
0.84\end{array}$ & $\begin{array}{l}\text { [SRI39] } \\
0.71\end{array}$ & $\begin{array}{l}\text { [SRI35] } \\
0.68\end{array}$ \\
\hline & $\begin{array}{l}\text { [SRI24] } \\
0.263\end{array}$ & $\begin{array}{l}\text { [SRI45] } \\
0.80\end{array}$ & $\begin{array}{l}\text { [SRI18] } \\
0.84 \\
(0.87)\end{array}$ & $\begin{array}{l}\text { [SRI46] } \\
0.53\end{array}$ & $\begin{array}{l}\text { [SRI38] } \\
0.80\end{array}$ & & $\begin{array}{l}\text { [SRI37] } \\
0.63\end{array}$ \\
\hline & $\begin{array}{l}\text { [SRI25] } \\
0.298\end{array}$ & & $\begin{array}{l}\text { [SRI42] } \\
0.27 \\
(0.26)\end{array}$ & & $\begin{array}{l}\text { [SRI40] } \\
0.43 \\
(0.39)\end{array}$ & & $\begin{array}{l}\text { [SRI47] } \\
0.63\end{array}$ \\
\hline & $\begin{array}{l}\text { [SRI29] } \\
0.678\end{array}$ & & & & $\begin{array}{l}\text { [SRI44] } \\
0.65 \\
(0.66)\end{array}$ & & $\begin{array}{l}\text { [SRI48] } \\
-0.05 \\
(-0.03)\end{array}$ \\
\hline & & & & & $\begin{array}{l}\text { [SRI49] } \\
0.79 \\
(0.81)\end{array}$ & & \\
\hline CFI & 0.788 & 0.913 & 0.688 & 0.901 & 0.721 & 0.935 & 0.878 \\
\hline $\begin{array}{l}\text { CFI after } \\
\text { modification }\end{array}$ & 0.987 & - & 0.90 & - & 0.971 & - & 0.971 \\
\hline \multirow{3}{*}{$\begin{array}{l}\text { RMSEA } \\
90 \% \mathrm{Cl}\end{array}$} & $\begin{array}{l}\text { RMSEA is } \\
0.164\end{array}$ & $\begin{array}{l}\text { RMSEA } \\
\text { is } 0.135\end{array}$ & $\begin{array}{l}\text { RMSEA is } \\
0.216\end{array}$ & $\begin{array}{l}\text { RMSEA } \\
\text { is } 0.137\end{array}$ & $\begin{array}{l}\text { RMSEA is } \\
0.224\end{array}$ & $\begin{array}{l}\text { RMSEA } \\
0.151\end{array}$ & $\begin{array}{l}\text { RMSEA is } \\
0.116\end{array}$ \\
\hline & $\begin{array}{l}\text { P-value } \\
0.00\end{array}$ & $\begin{array}{l}\text { P-value } \\
0.003\end{array}$ & $\begin{array}{l}\text { P-value } \\
0.00\end{array}$ & $\begin{array}{l}\text { P-value } \\
\text { is } 0.02\end{array}$ & $\begin{array}{l}\text { P-value is } \\
0.000\end{array}$ & $\begin{array}{l}\text { P-value } \\
0.005\end{array}$ & $\begin{array}{l}\text { P-value } \\
0.001\end{array}$ \\
\hline & $\begin{array}{l}(0.133 ; \\
0.197)\end{array}$ & $\begin{array}{l}(0.088 \\
0.185)\end{array}$ & $\begin{array}{l}(0.179 ; \\
0.254)\end{array}$ & $\begin{array}{l}(0.09 \\
0.188)\end{array}$ & $\begin{array}{l}(0.198 \\
0.252)\end{array}$ & $\begin{array}{l}(0.09 \\
0.281)\end{array}$ & $\begin{array}{l}(0.083 ; \\
0.151)\end{array}$ \\
\hline
\end{tabular}




\begin{tabular}{|c|c|c|c|c|c|c|c|}
\hline Scale & SRI-RC & SRI-PF & SRI-AS & SRI-SR & SRI-WB & SRI-AX & SRI-SF \\
\hline \multirow{4}{*}{$\begin{array}{l}\text { RMSEA } \\
90 \% \mathrm{Cl} \\
\text { after } \\
\text { modification }\end{array}$} & 0.042 & \multirow[t]{4}{*}{-} & RMSEA is & \multirow[t]{4}{*}{ - } & RMSEA is & \multirow[t]{4}{*}{ - } & \multirow{2}{*}{$\begin{array}{l}\text { RMSEA is } \\
0.35\end{array}$} \\
\hline & P-value & & & & & & \\
\hline & 0.564 & & $\begin{array}{l}\text { P-value } \\
0.002\end{array}$ & & $\begin{array}{l}\text { P-value is } \\
0.114\end{array}$ & & $\begin{array}{l}\text { P-value } \\
0.001\end{array}$ \\
\hline & $0.088)$ & & $\begin{array}{l}(0.086 ; \\
0.172)\end{array}$ & & $\begin{array}{l}(0.039 ; \\
0.109)\end{array}$ & & $\begin{array}{l}(0.000 ; \\
0.099)\end{array}$ \\
\hline
\end{tabular}

Italic values represent the factor loading after correlating residual errors of modification indices more than 15.

Cronbach's alpha was high for all subscales as well as for the summary scale and ranged between 0.73 and 0.89 (Table 2).

Table 2

Arabic SRI Questionnaire Reliability

\begin{tabular}{|llll|}
\hline Scale & Number $(\boldsymbol{n})$ & Mean \pm SD scores & Cronbach's alpha a \\
\hline SRI-RC & 8 items & $67.5 \pm 18.3$ & 0.8 \\
\hline SRI-PF & 6 items & $42.25 \pm 23.7$ & 0.796 \\
\hline SRI-AS & 7 items & $66.82 \pm 18.66$ & 0.729 \\
\hline SRI-SR & 6 items & $69.49 \pm 20.0$ & 0.792 \\
\hline SRI- WB & 5 items & $59.86 \pm 19.96$ & 0.820 \\
\hline SRI- AX & 9 items & $64.73 \pm 22.42$ & 0.872 \\
\hline SRI-SF & 8 items & $57.27 \pm 19.39$ & 0.761 \\
\hline SRI-SS & 7 scales & $60.98 \pm 16.0$ & 0.897 \\
\hline
\end{tabular}

External construct (nomological validity) was confirmed between each of the subscales of the Arabic SRI and subscales of the Arabic SF-36 (Table 3). The highest correlations were found between the Physical Functioning and the Social Functioning subscales of both instruments; $r=0.81$ and $r=0.74(P<0.01)$, respectively. Correlations were also high between the SRI-WB and SF-36-MH $(r=0.62)$ and the SRI-AX and SF-36-RE $(r=0.61)$ with statistical significance $(P<0.01)$. The lowest correlated subscales were the SRIPF and the SF-36-MH $(r=0.21)$. The correlation between the SRI-Summary Scale and the SF-36-Physical Health Component Summary $(r=0.66)$ was higher than the correlation between the SRI-Summary Scale and the SF-36-Mental Health Component Summary $(r=0.57)$, yet both were high. 


\begin{tabular}{|c|c|c|c|c|c|c|c|c|c|c|c|}
\hline & & \multicolumn{10}{|c|}{ SF-36 Scales } \\
\hline & & $\mathrm{PF}$ & $\mathrm{RP}$ & BP & GH & VT & SF & $\mathrm{RE}$ & MH & MHC & PHC \\
\hline \multirow[t]{8}{*}{ SRI Scales } & RC & .406 & .402 & .331 & .330 & .404 & .438 & .384 & .338 & & \\
\hline & PF & .812 & .608 & .198 & .345 & .367. & .600 & .401 & 212 & & \\
\hline & AS & .312 & .313 & .483 & .464 & .277 & .340 & .388 & .329 & & \\
\hline & SR & .522 & .551 & .335 & .502 & .336 & .593 & .562 & .470. & & \\
\hline & $\mathrm{AX}$ & .406 & .544 & .254 & .490 & .416 & .489 & .618 & . & & \\
\hline & WB & .480 & .579. & .406 & .553. & .512 & .595. & .574 & .626 & & \\
\hline & $\mathrm{SF}$ & .717 & .644 & .490 & .433 & .389 & .740 & .562 & .358 & & \\
\hline & SS & .661 & .658 & .444 & .557 & .477 & .687 & .642 & .499 & 0.571 & 0.663 \\
\hline
\end{tabular}

Notes:

The SRI scales: Respiratory Complaints (RC), Physical Functioning (PF), Attendant symptoms and Sleep (AS), Social Relationships (SR), Anxiety (AX), Psychosocial Well-being (WB), Social Functioning (SF), and Summary Scale (SS).

The SF-36 scales: Physical Functioning (PF), Role Physical (RP), Body Pain (BP), General Health (GH), Vitality (VT), Social Functioning (SF), Role Emotional (RE), Mental Health (MH), Physical Health Component (PHC), and Mental Health Component (MHC).

All correlations in the table are statistically significant at a P-value $<0.01$ level.

Highest correlations in raw are italic. Highest correlations in column are bold. Highest correlations both in raw and column are bold and italic. Summary scales are in light gray.

\section{Discussion}

The availability of a standardized, valid and reliable tool to assess HRQL in patients on long-term HMV is a fundamental goal for clinical management of patients with chronic respiratory insufficiencies. It is also important for information exchange with results that are comparable across different studies and settings. Our finding that one common factor explains $63 \%$ of the total variation in the SRI questionnaire corroborates those of the original developers in the German language (59.8\%). Similarly, we found high correlations between comparable subscales of the SRI and the SF-36, and this is also comparable to the German version ([17] Windisch et. al, 2003). This implies that the Arabic SRI is capable of accurately and consistently measuring certain aspects of the quality of life available in the SF-36, considered the gold standard tool for assessing generic HRQL. To this end, high correlations were attained between: (a) the Physical Functioning subscales of both SRI and SF-36, (b) the SRI-WB and the SF-36-MH, as well as (c) the SRI-AX and the SF-36-RE. The direction and strength of these correlations are expected as they measure similar aspects of quality of life. In contrast, subscales measuring different aspects of quality of life such as SRI-RC and SRI-AS had low correlations with SF-36 subscales, as the latter does not explicitly measure respiratory complaints and sleep disturbances. Moreover, moderately to high correlations 
between the SRI-SF and the majority of the SF-36 subscales were reached explaining that the extent of social involvement can be impacted by the level of the physical activity and psychological well-being. Additionally, correlations between the SRI and SF-36 subscales were comparable to the original SRI with even higher correlations in the Arabic version between the SRI-PF and the SF-36-RP, and between the SRIAX and the SF-36-RE. Likewise, higher correlation between the Summary score of the Arabic SRI and the SF-36 Physical Health Component Summary was noted as compared to the original version ([17] Windisch et. al, 2003).

The Arabic SRI also had similar strength and direction of correlations with the SF-36 when compared to other versions validated in different cultures where nomological validity was assessed, with some exceptions ([19] Ghosh et. al, 2011; [18] Lo'pez-Campos, 2008; Markussen et. al, 2015; Oga et. al, 2017). The Arabic version had higher correlations than the Japanese one between the Physical and Social Functioning subscales of both instruments, and between the SRI-AX and the SF-36-RE (Oga et. al, 2017). The Arabic version also had higher correlation than the Spanish ([18] Lo'pez-Campos, 2008) and Norwegian (Markussen et. al, 2015) versions between the SRI-AX and SF-36-RE.

When assessing reliability, all subscales and the summary scale had high internal consistency where Cronbach's alpha values were almost identical to the original version ([17] Windisch et. al, 2003), with the highest Cronbach's alpha being for the total summary scale (0.897). Cronbach's alpha for the majority of the subscales were also comparable to the SRI validated in other languages and contexts including the English (Ghosh et. al, 2011), Spanish ([18] Lo' pez-Campos, 2008), Norwegian ([20] Markussen et. al, 2015) and the Chinese version ([22] Chen, Guan, Wu, et al., 2017). Yet, it was higher than the Greece ([21] Tsara et. al, 2017) and the Japanese version ([23] Oga et. al, 2017) on some subscales including the SRIPF, SRI-AS and SRI-SR, and on the SRI-AX for the Greece version only.

The study findings need to be interpreted considering certain limitations and within the Lebanon language context. Tracheostomized patients were not included in this validation study to make it comparable with the original study, keeping in mind that patients receiving mechanical ventilation via tracheostomy tubes have different characteristics than those receiving it non-invasively and thus have implications on their HRQL. Moreover, forty-eight percent of patients did not respond to the item 31 "My marriage/relationship is suffering because of my illness" since they were not married or in a relation at time of filling the questionnaire. Given that the item 31 is one question in determining the social functioning of a patient, it is believed that the response to that item would be in same direction with the entire SRI-SF subscale. Therefore, the "not applicable" answers of the item 31 were substituted by the SRISF mean of the same patient calculated based on the responses of the remaining 7 items of that particular subscale. Following in-depth analysis of the inter-item correlations, we noted extreme high correlations between the items (34: I am often irritable) and (40: I am often nervous), although the two items should capture different meanings; upon revisiting the translation of both items, the team identified a more accurate term for the word "nervous" in item 40 which is "Mowattar- पर्य". Subsequently, it is recommended for all researchers willing to use the Arabic SRI version in future research to replace and

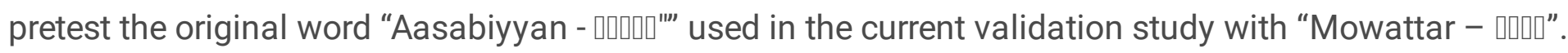


The current Arabic SRI that was tested among a Lebanese population may also undergo adaptation to other dialects in the Arab language. The low correlations between the subscales of the SRI and the SF-36 measuring different domains indicate the necessity of having a tool that assesses unique concepts of HRQL related to patients with chronic respiratory failure that are not available in the SF-36 or other tools. For instance, the SRI-RC and the SRI-AS subscales, which assess concepts specific for the SRI population, had low correlations with all SF-36 subscales.

The SRI is a relatively newly developed questionnaire that measures HRQL among patients receiving HMV with an ability to detect diversities between different diagnostic groups. The HRQL is highly dependent on the underlying disease. Although differences in the scores of some subscales and the summary scale were noted among different diagnostic groups thus suggesting a varying quality of life, it was not statistically proved in our study. This is most likely referred to the significant imbalance in the sample size as the majority of patients have COPD $(n=114,76.5 \%)$.

The transcultural adaptation of the Arabic SRI is the outcome of forward and backward translation procedures, resulting in a high comparability with the original German version. As part of the transcultural adaptation processes, and unlike the original version that was self-administered, the administration of the Arabic version was surveyor-assisted to ensure the best questionnaire administration technique based on our sample characteristics. Assisted administration was adopted to avoid major discrepancies in the mode of administration due to the relatively higher proportion of elderly subjects, and substantial proportion of patients with low education status in our sample.

\section{Conclusion}

In conclusion, the Arabic SRI version is a valid and reliable tool with high psychometric properties similar to the original German version. Given that formal Arabic was used in the translation (as opposed to Lebanese dialect), the instrument is valid to be used in Arab-speaking populations. Such a validated instrument will allow a reflective assessment of the quality of life of patients receiving HMV in future epidemiological studies or clinic-based settings to help delineate factors influencing a better quality of life, evaluate interventions and ultimately inform the allocation of resources within the Lebanese context, and possibly other Arab countries.

\section{Declarations}

\section{a. Ethics approval and consent to participate}

The study was approved by the Institutional Review Board at the American University of Beirut, Lebanon. The informed consent forms were obtained from all participants.

\section{IRB Guideline Statement:}


The American University of Beirut and its Institutional Review Board, under the Institution's Federal Wide Assurance with OHRP, comply with the Department of Health and Human Services (DHHS) Code of Federal Regulations for the Protection of Human Subjects ("The Common Rule") 45CFR46, subparts A, B, $C$, and D, with 21CFR56; and operate in a manner consistent with the Belmont report, FDA guidance, Good Clinical Practices under the ICH guidelines, and applicable national/local regulations.

The statement for "ethical approval" and the "informed consent" are attached in the system.

\section{b. Consent for publication}

Not applicable.

\section{c. Availability of data and materials}

The datasets used and/or analysed during the current study available from the corresponding author on reasonable request.

The authors are happy to share the datasets if the manuscript passes the screening phase and reaches preliminary acceptance.

\section{d. Competing interests}

All authors do not have any conflict of interest.

\section{e. Funding}

The study was funded by the Conseil National de la Recherche Scientifique (CNRS) - Lebanon to cover data collection costs.

Fund reference number: 01-08-15

Role of the CNRS: The CNRS had no role in the preparation of data or the manuscript.

\section{f. Authors' contributions}

Lilian, Abla, Marwan, and Mohamad developed the tools. Marwan \& Rania conducted statistical analysis, and wrote the manuscript. Lilian, Abla, Salah and Mohamad critically revised and provided feedback on the manuscript. Lilian provided technical feedback and advise on psychometric analysis. Salah and Mohamad provided expert advice (pulmonary related) for the analysis.

\section{g. Acknowledgements}

We acknowledge the support of Mrs. Ghina Al-Ghosh for preparing and assisting in logistics for data collection. 


\section{References}

1. Testa MA, Simonson DC. Assessment of quality-of-life outcomes. N Engl J Med 1996; 334: 835-40

2. Higginson IJ, Carr AJ. Measuring quality of life: using quality of life measures in the clinical setting. BMJ 2001; 322: 1297-300

3. Bergner Marilyn, Ruth A. Bobbitt, William B. Carter, and Betty S. Gilson. The Sickness Impact Profile: development and final revision of a health status measure. Medical Care August 1981; XIX, 8: 787805

4. John E. Ware, JR. and Cathy Donal Sherbourne. The MOS 36-item short-form health survey (SF-36). I. Conceptual framework and item selection. Med Care 1992; 30: 473-483

5. Guyatt GH, Berman LB, Townsend M, Pugsley SO, Chambers LW. A measure of quality of life for clinical trials in chronic lung disease. Thorax 1987; 42: 773-8.

6. Sullivan C.E., Issa F.G., Berthon-Jones M., Eves L. Reversal of obstructive sleep apnoea by continuous positive airway pressure applied through the nares. Lancet 1981; 1: 862.865.

7. Bach JR, Alba AS. Management of chronic alveolar hypoventilation by nasal ventilation. Chest 1990; 97: $52-57$

8. Leger P, Bedicam JM, Cornette A, Reybet-Degat O, Langevin B, Polu JM, Jeannin L, Robert D. Nasal intermittent positive pressure ventilation. Long-term follow-up in patients with severe chronic respiratory insufficiency. Chest 1994; 105: 100-105

9. Meecham Jones DJ, Paul EA, Jones PW, Wedzicha JA. Nasal pressure support ventilation plus oxygen compared with oxygen therapy alone in hypercapnic COPD. Am J Respir Crit Care Med 1995; 152: $538-544$

10. Simonds AK, Elliott MW. Outcome of domiciliary nasal intermittent positive pressure ventilation in restrictive and obstructive disorders. Thorax 1995; 50: 604-609

11. Anonymous. Clinical Indications for Noninvasive Positive Pressure Ventilation in Chronic Respiratory Failure Due to Restrictive Lung Disease, COPD, and Nocturnal Hypoventilation-A Consensus Conference Report (CHEST 1999; 116:521-534)

12. Mehta S, Hill NS. Noninvasive ventilation. Am J Respir Crit Care Med 2001; 163: 540-577

13. M.L. Duiverman, J.B. Wempe, G. Bladder, H.A.M. Kerstjens and P.J. Wijkstra. Health related quality of life in COPD patients with chronic respiratory failure. Eur Respir J 2008; 32: 379-386 DOI: 10.1183/09031936.00163607

14. Elliott MW, Simonds AK, Carroll MP, Wedzicha JA, Branthwaite MA. Domiciliary nocturnal nasal intermittent positive pressure ventilation in hypercapnic respiratory failure due to chronic obstructive lung disease: effects on sleep and quality of life. Thorax 1992; 47: 342-8.

15. Sivasothy P, Smith IE, Shneerson JM. Mask intermittent positive pressure ventilation in chronic hypercapnic respiratory failure due to chronic obstructive pulmonary disease. Eur Respir J 1998; 11: 34-40. 
16. Pehrsson K, Olofson J, Larsson S, Sullivan M. Quality of life of patients treated by home mechanical ventilation due to restrictive ventilatory disorders. Respir Med 1994; 88: 21-6.

17. Wolfram Windisch, Klaus Freidel, Bernd Schucher, Hansjo“rg Baumann, Matthias Wiebele, Heinrich Matthys, Franz Petermann. The Severe Respiratory Insufficiency (SRI) Questionnaire: A specific measure of health-related quality of life in patients receiving home mechanical ventilation. Journal of Clinical Epidemiology 2003; 56: 752-759. doi: 10.1016/S0895-4356(03)00088-X

18. Jose Luis Lo'pez-Campos, Inmaculada Failde, Juan F. Masa, Jose M. Benı́tez-Moya, Emilia Barrot, Ruth Ayerbe, Antonio Leo'n-Jim_enez, Wolfram Windisch. Transculturally adapted Spanish SRI Questionnaire for home mechanically ventilated patients was viable, valid, and reliable. Journal of Clinical Epidemiology 2008. doi: 10.1016/j.jclinepi.2007.09.002

19. Dipansu Ghosh, Peter Rzehak, Mark W Elliott, Wolfram Windisch. Validation of the English Severe Respiratory Insufficiency Questionnaire. ERJ Express. Published on December 19, 2011 as doi: 10.1183/09031936.00152411

20. Markussen H, Lehmann S, Nilsen RM, Natvig GK. The Norwegian version of the Severe Respiratory Insufficiency (SRI) Questionnaire. International Journal of Nursing Practice 2015; 21: 229-238.

21. Tsara V, Michailidis V, Perantoni E1, Nena E2, Moysiadis N, Windisch W, Steiropoulos P. HIPPOKRATIA 2017, 21, 4: 186-190

22. Chen R, Guan L, Wu W, et al. The Chinese version of the Severe Respiratory Insufficiency questionnaire for patients with chronic hypercapnic chronic obstructive pulmonary disease receiving non-invasive positive pressure ventilation. BMJ Open 2017; 7:e017712. doi:10.1136/ bmjopen-2017017712

23. Toru Oga, Hiroyuki Taniguchi, Hideo Kita, Tomomasa Tsuboi, Keisuke Tomii, Morihide Ando, Eiji Kojima, Hiromi Tomioka, Yoshio Taguchi, Yusuke Kaji, Ryoji Maekura, Toru Hiraga, Naoki Sakai, Tomoki Kimura, Michiaki Mishima, Wolfram Windisch, Kazuo Chin. Validation of the Japanese Severe Respiratory Insufficiency Questionnaire in hypercapnic patients with non-invasive ventilation. Respiratory Investigation; 55 (2017): 166-172

24. Nunnally JC, Bernstein I. Psychometric theory. 3rd ed. New York: McGraw-Hill; 1994.

25. Brown, T. A., Moore, M. T. Confirmatory factor analysis. In Hoyle, R. H. (Ed.), Handbook of structural equation modeling. New York: Guilford Press (2012). Pp. 361-379.

\section{Figures}




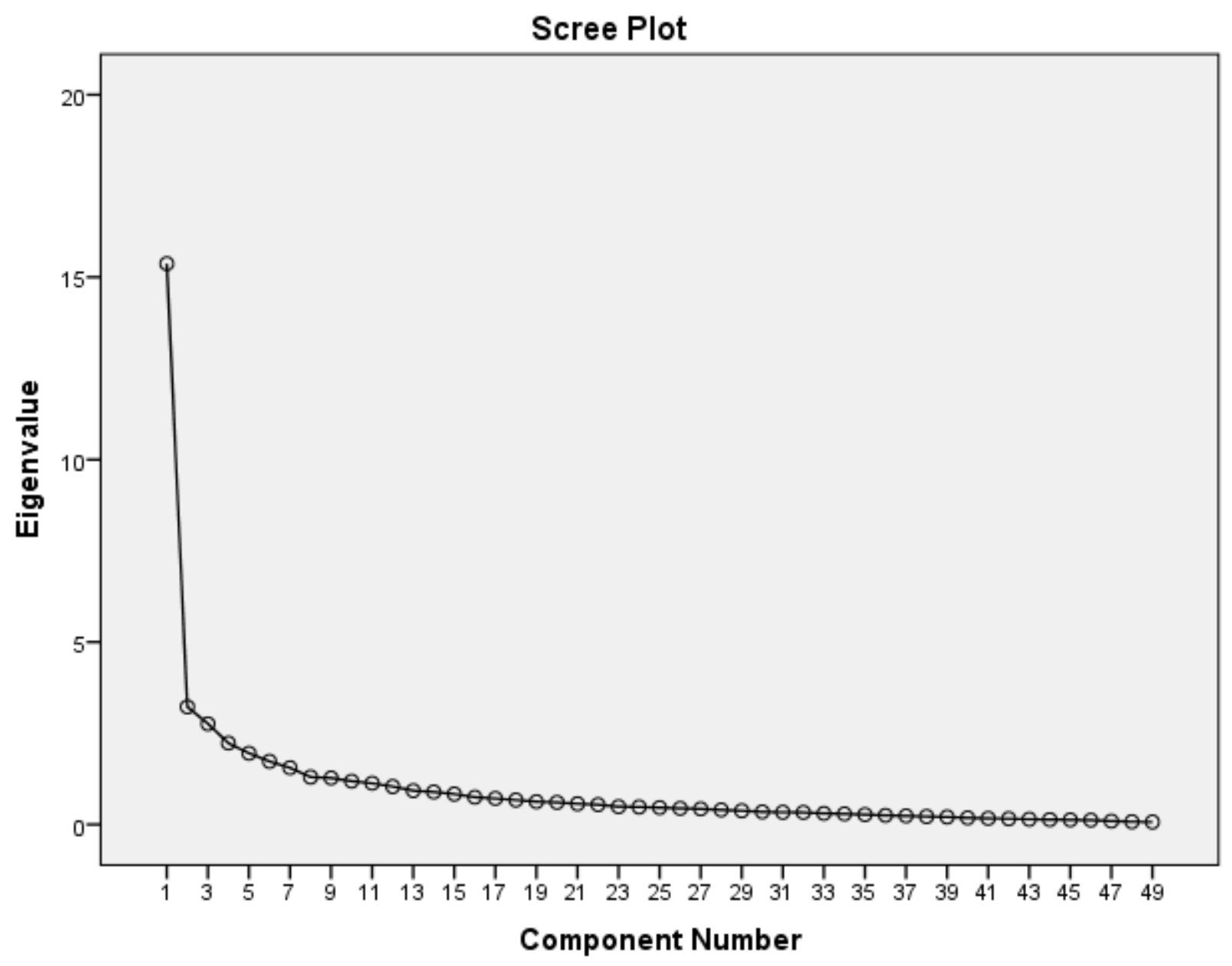

Figure 1

Scree plot using the Principal Component Analysis 


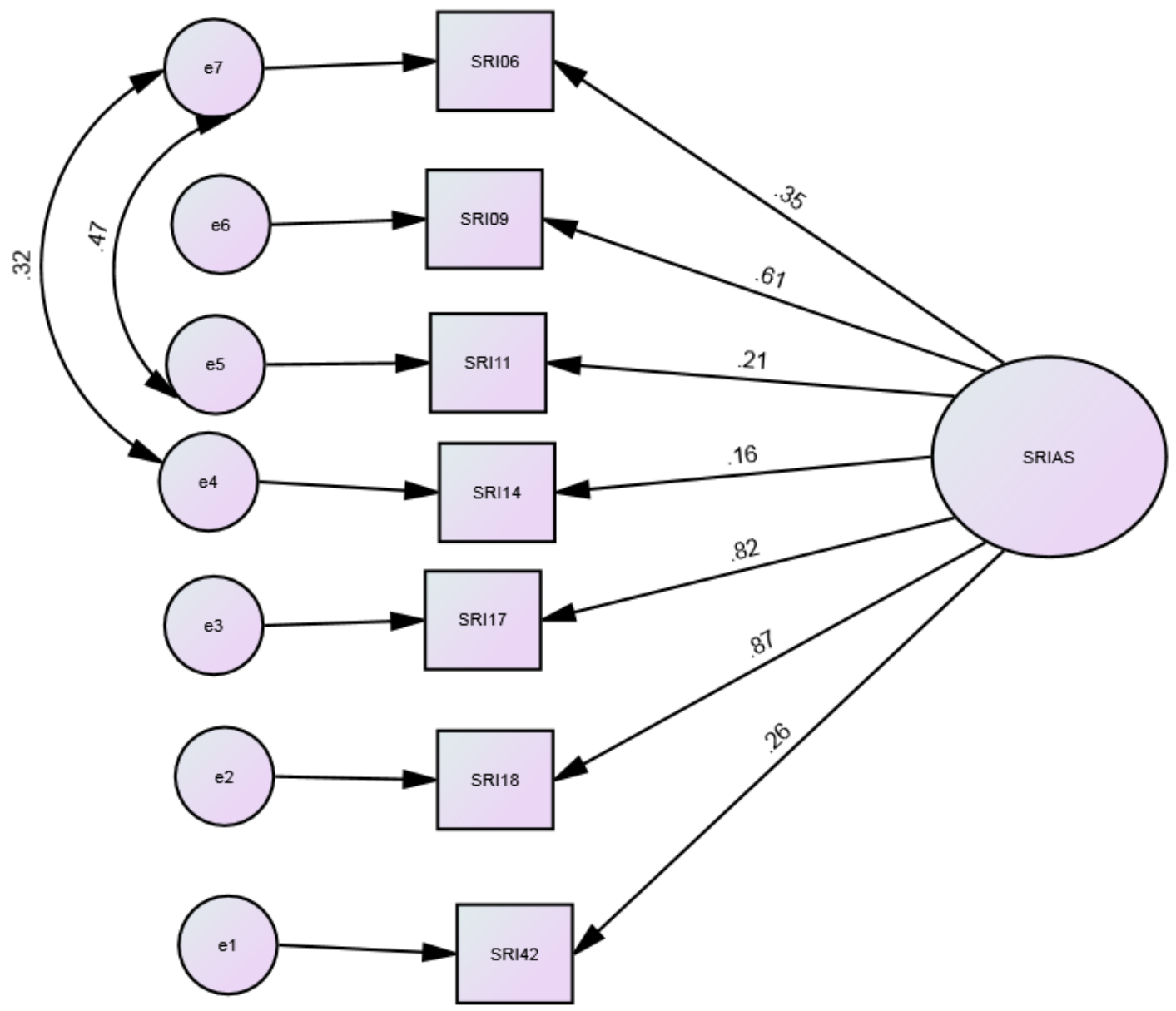

Figure 2

Construct of the SRI-AS Scale after Modification

\section{Supplementary Files}

This is a list of supplementary files associated with this preprint. Click to download. 
- ArabicSRIValidationEnglishInformedConsent.pdf

- ArabicSRIValidationDemographicQuestionnaire.pdf 